\title{
CUT-OFF VALUE ADENOSINE DEAMINASE ACTIVITY IN CEREBROSPINAL FLUID FOR DIAGNOSIS OF TUBERCULOUS MENINGITIS
}

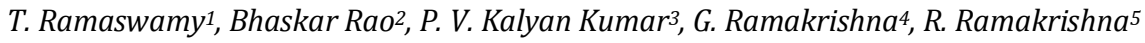

${ }^{1}$ Associate Professor, Department of Respiratory Medicine, Anantpuram Government Medical College, Anantpuram, Andhra Pradesh, India.

${ }^{2}$ Associate Professor, Department of Respiratory Medicine, RIMS, Kadapa, Andhra Pradesh, India.

${ }_{3}^{3}$ Associate Professor, Department of Respiratory Medicine, KMCH, Guntur, Andhra Pradesh, India.

${ }^{4}$ Associate Professor, Department of General Medicine, KMCH, Guntur, Andhra Pradesh, India.

5 Professor and HOD, Department of Respiratory Medicine, NRI Medical College, Guntur, Andhra Pradesh, India.

\section{BACKGROUND}

\section{ABSTRACT}

Tuberculous meningitis is a serious clinical problem with significant morbidity and mortality.

The objectives of the study are- 1 . to estimate the cerebrospinal fluid adenosine deaminase levels in suspected cases of meningitis and 2. to evaluate the utility of Cerebrospinal-ADA levels as a diagnostic test in tuberculous meningitis.

\section{MATERIALS AND METHODS}

It is a descriptive study. Adenosine deaminase activity (ADA) was studied in cerebrospinal fluid of 42 cases of tuberculous meningitis, 13 cases of pyogenic meningitis, 19 cases of aseptic meningitis and 20 cases of controls (patients without any neurological problem who were given spinal anaesthesia). Sample size taken for convenience.

\section{RESULTS}

The mean cerebrospinal fluid adenosine deaminase activity was $13.1 \pm 1.96 \mathrm{U} / \mathrm{L}$ in tuberculous meningitis, $5.91 \pm 1.27 \mathrm{U} / \mathrm{L}$ in pyogenic meningitis, $2.62 \pm 1.03$ for aseptic meningitis and $1.45 \pm 0.44 \mathrm{U} / \mathrm{l}$ for controls. The adenosine deaminase activity in tuberculous meningitis cases was significantly higher. The sensitivity and specificity of this test for diagnosis of tuberculous meningitis was $100 \%$ and $98.44 \%$ respectively with ADA value of more than $12 \mathrm{U} / \mathrm{L}$.

\section{CONCLUSION}

Adenosine deaminase activity in CSF is a quick, relatively inexpensive and simple procedure, can be of great value in the diagnosis of tuberculous meningitis, help in earlier institution of suitable treatment and thereby prevent morbidity, mortality and other complications.

\section{KEY WORDS}

Cerebrospinal Fluid; Adenosine Deaminase; Tuberculous Meningitis.

HOW TO CITE THIS ARTICLE: Ramaswamy T, Rao B, Kumar PVK, et al. Cut-off value adenosine deaminase activity in cerebrospinal fluid for diagnosis of tuberculous meningitis. J. Evolution Med. Dent. Sci. 2019;8(03):177-179, DOI: $10.14260 /$ jemds/2019/39

\section{BACKGROUND}

Mycobacterium tuberculosis (TB) is a major cause of death worldwide. Tuberculosis is capable of infecting any organ of the body, and even the heart is no exception. The global increase in the incidence of tuberculosis in both immunocompetent as well as immunocompromised individuals is a major health issue of world wide. Factors that have contributed to this augmentation of the CNS tuberculosis with HIV infection, multi-drug-resistant tuberculosis, advanced age, alcoholism, I.V drug abuse, poor quality of life, malnutrition, malignancies like lymphoma and immuno-suppressive medication also contribute to increased susceptibility.

'Financial or Other Competing Interest': None.

Submission 15-10-2018, Peer Review 08-01-2019,

Acceptance 14-01-2019, Published 21-01-2019.

Corresponding Author:

Dr. T. Ramaswamy,

Associate Professor,

Department of Respiratory Medicine,

Anatpuram Government Medical College,

Anatpuram, Andhra Pradesh, India.

E-mail: ramaswamytdr@gmail.com

DOI: $10.14260 /$ jemds $/ 2019 / 39$
Involvement of the central nervous system by $M$. tuberculosis is the most hazardous type of systemic tuberculosis because of its high mortality and morbidity rate and possible serious neurological complications like paralysis and paraplegia and its sequelae. ${ }^{1}$ It occurs in all age groups, but $60-70 \%$ of patients are below the age of 20 years. CNS tuberculosis occurs in $2-5 \%$ of all patients with tuberculosis and in $10 \%$ of those with AIDS-related TB. ${ }^{2}$ Co-existence of extra-neural tuberculosis is reported along with $50 \%$ of cases of neuro-tuberculosis in the literature, which may be a clue to the diagnosis of CNS tuberculosis.

The gold standard of diagnosing TBM is AFB culture of CSF fluid, which will take more than 2 weeks for the confirmation. While CSF ADA analysis is reliable alternative for early diagnosis of TBM, which will take hours for diagnosis with good sensitivity and specificity.

\section{Staging of TBM}

Medical Research Council (MRC) Staging of TBM 19483,4

a. Stage 1: Prodromal phase with no definite neurological symptoms or signs.

b. Stage 2: Signs of meningeal irritation with slight or no loss of consciousness and minor (cranial) nerve palsies or neurological deficits. 
c. Stage 3: Severe loss of consciousness, stupor, coma, convulsions, gross paresis or involuntary movements.

\section{CSF Adenosine Deaminase and its Role in Tuberculous Meningitis}

Adenosine deaminase called ADA by Spencer et $\mathrm{al}^{5}$ is an enzyme of purine catabolism which catalyses the pathway from adenosine to inosine.

Its distribution in human body is everywhere but its physiologic role is especially important in lymphoid tissues. It has got vital role in differentiation, proliferation (or) both of lymphoid cells. Specific activity of this enzyme is elevated in T lymphocytes than in B cells. Hereditary deficiency of ADA is associated with malfunctioning of hormonal and cellular immunity. ADA activity is related to the development of $\mathrm{T}$ lymphocytes and not to the total lymphocyte count.

The enzyme activity is high in infections where immunity is cell mediated immunity like tuberculosis. It has been widely used for diagnosis of tuberculosis pleural, pericardial and peritoneal effusions and has been accepted in it as supportive criteria tubercular meninigitis. ${ }^{6}$

CSF ADA activity measured by calorimetric method. One unit of activity represents deamination of one micromole of adenosine/ $\min$ at $370 \mathrm{c}$ and is expressed as $1 \mathrm{U} / \mathrm{L}^{7}$

\section{Aims and Objectives}

1. Estimation of the cerebrospinal fluid adenosine deaminase levels in clinically suspected cases of meningitis and comparing with controls.

2. To evaluate the management of tuberculous meningitis.

\section{MATERIALS AND METHODS}

It is a descriptive study. A total of seventy-four cases clinically suspected of meningitis, admitted in Anantapur government medical college and Katuri Medical College during the period between April 2016 to February 2018. Sample size taken for convenience.

\section{Inclusion criteria}

1. Age more than 8 years.

2. New cases were only taken.

3. Patient should not have received any therapy outside the hospital.

\section{Exclusion Criteria}

Some cases whose clinical picture is similar to meningitis like subarachnoid haemorrhage, cerebral malaria were excluded.

Following the above said criteria 42 cases of tuberculous meningitis, 13 cases of pyogenic meningitis, 19 cases of aseptic meningitis and 20 cases of controls (Patients without any neurological problem who were given spinal anaesthesia) were included in the study.

\section{Diagnosis of Tubercular Meningitis}

1. Diagnosis was made based on CSF fluid ADA levels.

2. All patients' chest radiographs were done and sputum for AFB staining was performed.

\section{Study Design and Statistical Analysis}

The study design is descriptive study and Results are expressed as mean \pm SD. To compare the mean ADA activity between the TBM, non-TBM infectious meningitis and noninfectious Neurological disorders groups, the Kruskal-Wallis Test which is a non-parametric analysis of variance \{ANOVA\}) with the Dunnett post-test analysis was done

A p-value $<0.05$ was considered significant. A cut-off value of ADA activity for TBM patients was calculated from the mean plus SD of ADA activity in the non-TBM meningitis group.

The sensitivity (True Positive Rate) for the test was calculated as: (The number of samples in the TBM group with ADA activity $\geq$ (mean \pm SD) of ADA activity in the non-TBM infectious meningitis group divided by the total number of samples in TBM group) $\times 100$.

The specificity (True Negative Rate) for the test was calculated as the number of samples in non-TBM infectious meningitis group with ADA activity $<$ (mean \pm SD) of ADA activity in the non-TBM infectious meningitis group divided by the total number of samples in non- TBM infectious meningitis group) $\times 100$.

\section{Cut-Off Value Calculation}

A cut off value of $12 \mathrm{u} / \mathrm{l}$ was calculated using ROC [Receiver Operating Characteristic] curve for the diagnosis of TBM. 42 cases of TBM had ADA above the cut off value $(12 \mathrm{u} / \mathrm{l})$ and 32 cases of NON-TBM had ADA below the cut off value (12 $\mathrm{u} / \mathrm{l}$ )

\section{RESULTS}

\begin{tabular}{|c|c|c|}
\hline Sex & No. of Cases & Percentage \\
\hline Male & 44 & 59.46 \\
\hline Female & 30 & 40.54 \\
\hline Total & $\mathbf{7 4}$ & $\mathbf{1 0 0 . 0 0}$ \\
\hline \multicolumn{2}{|c|}{ Table 1. Sex Wise Distribution of Cases }
\end{tabular}

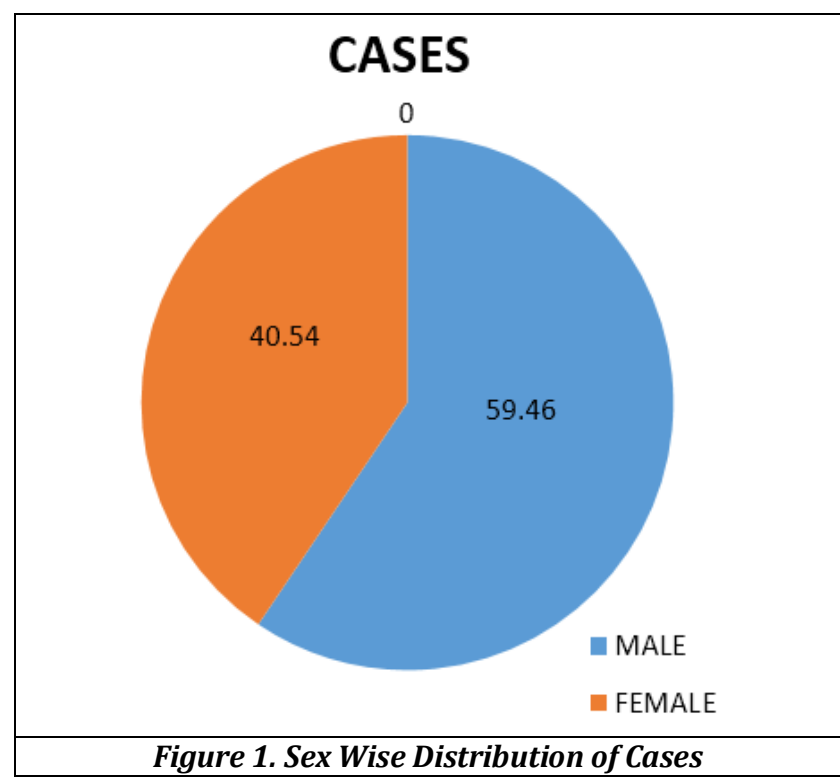

\begin{tabular}{|c|c|c|}
\hline Immunization Status & No. of Cases & Percentage \\
\hline BCG Vaccinated & 26 & 35.14 \\
\hline Not Vaccinated & 48 & 64.86 \\
\hline Total & 74 & $\mathbf{1 0 0 . 0 0}$ \\
\hline
\end{tabular}


Table 2. Immunization Wise Distribution of Cases

The table 2 shows that tuberculous meningitis is less common in BCG vaccinated individuals

\begin{tabular}{|c|c|c|}
\hline Risk Factor & No. of Cases & Percentage \\
\hline Past History of Tuberculosis & 22 & 29.73 \\
\hline Immunocompromised Status & & \\
\hline Diabetes & 3 & 4.05 \\
\hline HIV Infection & 4 & 5.41 \\
\hline $\begin{array}{c}\text { Evidence of Extra Neural } \\
\text { Tuberculosis }\end{array}$ & 5 & 39.19 \\
\hline \multicolumn{2}{|c|}{ Table 3. Analysis of Risk Factors for Tuberculous } \\
Meningitis
\end{tabular}

Table 3 suggest past history of tuberculosis and Immunocompromised status contribute to 40 percentage of CSF tuberculosis.

\begin{tabular}{|c|c|c|c|c|}
\hline \multirow{2}{*}{ Group } & \multirow{2}{*}{$\begin{array}{l}\text { No. of } \\
\text { Cases }\end{array}$} & \multicolumn{3}{|c|}{ CSF ADA Levels (U/L) } \\
\hline & & Mean & SD & Range \\
\hline A-TB Meningitis & 42 & 13.9 & 1.96 & $10.2-17.2$ \\
\hline B-Pyomeningitis & 13 & 5.91 & 1.27 & $3-10.1$ \\
\hline $\begin{array}{l}\text { C-Aseptic } \\
\text { Meningitis }\end{array}$ & 19 & 2.62 & 1.03 & $1.2-4.9$ \\
\hline D-Controls & 20 & 1.45 & 0.44 & $1-2.5$ \\
\hline \multicolumn{5}{|c|}{ Table 4. CSF ADA Levels in Different Groups } \\
\hline \multicolumn{5}{|c|}{ A Vs $C, t=18.71, d f=42, p<0.001$} \\
\hline
\end{tabular}

Table 4 suggest Mean CSF ADA levels in tuberculous meningitis groups is significantly higher as compared to pyogenic meningitis group, aseptic meningitis group and control groups.

\begin{tabular}{|c|c|c|c|c|c|}
\hline 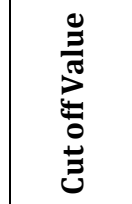 & 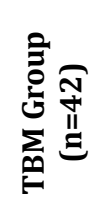 & 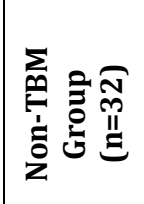 & 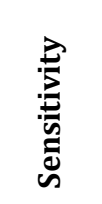 & 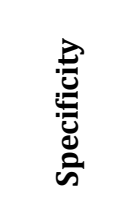 & 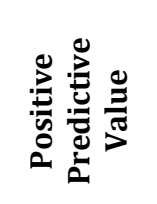 \\
\hline $12 \mathrm{U} / \mathrm{L}$ & 42 & 1 & $100 \%$ & $97.44 \%$ & $96.77 \%$ \\
\hline \multicolumn{6}{|c|}{$\begin{array}{l}\text { Table 5. Calculation of Sensitivity, Specificity and Positive } \\
\text { Predictive Value for CSF ADA in Diagnosis of Tuberculous } \\
\text { meningitis }\end{array}$} \\
\hline \multicolumn{6}{|c|}{$\begin{array}{c}\text { TB } 42 \text { Cases, PYOM } 13 \text { Cases, ASPM 19, Total Cases 74, } \\
\text { Controls } 20\end{array}$} \\
\hline \multicolumn{6}{|c|}{$\begin{array}{l}\text { Taking CSF ADA cut off value } 12 \mathrm{U} / \mathrm{L} \text { and comparing with } \\
\text { CSF ADA levels in controls, a sensitivity of } 100 \% \text {, specificity } \\
\text { of } 98.44 \% \text {, with a positive predictive value of } 100 \% \text { is } \\
\text { obtained for this test. }\end{array}$} \\
\hline
\end{tabular}

\section{DISCUSSION}

Forty-two patients of tuberculous meningitis are studied in detail and diagnostic ability of ADA is evaluated in comparison with 13 cases of pyogenic meningitis, 19 cases of aseptic meningitis and 20 patients without any neurological disorders who needed spinal anaesthesia.

According to the present study, the incidence in males was $60 \%$ and in females $40 \%$.

Mean CSF ADA level was significantly higher in TBM patients $(13.9 \pm 1.96)$ as compared to pyogenic meningitis (5.91 \pm 1.27$)$, aseptic meningitis $(2.66 \pm 1.03)$ and controls
$(1.45 \pm 0.44)$. The adenosine deaminase test is a simple and low-cost procedure that may be included as a routine laboratory method, especially in those countries with a high prevalence of tuberculosis. It is therefore, evident that determining ADA level in the CSF is a simple and very useful test for the early diagnosis of tuberculous meningitis.

Similar study done by Raviraj ${ }^{8}$ to find out the lower cut off value of CSF-ADA in the patients' diagnosis of tuberculous meningitis was $6.65 \mathrm{U} / \mathrm{L}$ when compared to the present study of $12 \mathrm{U} / \mathrm{L}$. The study done by Raviraj et al taken in to consideration of TB meningitis and pyogenic meningitis. But in our present study we have taken TBM along with pyogenic and aseptic meningitis.

\section{CONCLUSION}

This study was undertaken to evaluate the diagnostic utility of CSF-ADA activity in tuberculous meningitis. Thirty cases of tuberculous meningitis were studied. The mean CSF ADA value in tuberculous meningitis was statistically significant ( $p<0.001$ ) when compared to the CSF ADA values in pyogenic meningitis, aseptic meningitis and controls.

Taking the cut-off value of $12 \mathrm{U} / \mathrm{L}$, the CSF ADA estimation in tuberculous meningitis has a sensitivity of $100 \%$ and specificity of $98.44 \%$ in the present study.

Though the number of the controls, pyogenic meningitis and aseptic meningitis cases in this study is small, adenosine deaminase activity in CSF is a rapid, relatively inexpensive and easy procedure, can be of great value in the early diagnosis of tuberculous meningitis and helps in earlier institution of appropriate treatment thereby preventing mortality and complications.

\section{REFERENCES}

[1] De Almeida SM, Nogueira MB, Raboni SM, et al. Laboratorial diagnosis of lymphocytic meningitis. Braz J Infect Dis 2007;11(5):489-95.

[2] Chakraborty AK. Epidemiology of tuberculosis: current status in India. Indian J Med Res 2004;120(4):248-76.

[3] Kennedy DH, Fallon RJ. Tuberculous meningitis. JAMA 1979;241(3):264-8.

[4] Streptomycin treatment of tuberculous meningitis. Lancet 1948;1(6503):582-96.

[5] Rana SV, Singhal RK, Singh K, et al. Adenosine deaminase levels in cerebrospinal fluid as a diagnostic test for tuberculous meningitis in children. Indian J Clin Biochem 2004;19(2):5-9.

[6] Choi SH, Kim YS, Bae IG, et al. The possible role of cerebrospinal fluid adenosine deaminase activity in the diagnosis of tuberculous meningitis in adults. Clin Neurol Neurosurg 2002;104(1):10-5.

[7] Sinha PK, Sinha BB, Sinha ARS. Diagnosing tuberculous pleural effusion: comparative sensitivity of mycobacterial cultural, histopathology and ADA activity. JAPI 1985;33:64-6.

[8] Raviraj, Henry RA, Rao GG. Determination and validation of a lower cut off value of cerebrospinal fluid adenosine deaminase (CSF-ADA) activity in diagnosis of tuberculous meningitis. J Clin Diagn Res 2017;11(4):OC22-4. 